\section{Fe-Mo System}

The $(\alpha \mathrm{Fe}) / \lambda / \mu$ invariant at $927^{\circ} \mathrm{C}$ was labeled " $977^{\circ} \mathrm{C}$ " and shown at that incorrect temperature in Fig. 1 on page 359 in Vol. 3, No. 3 of the Bulletin. The revised diagram below replaces Fig. 1. The revised set of tear-out diagrams on pages 113-114 in this issue, which are plotted in both atomic and weight percent, replace those on pages 383-384 of Vol. 3, No. 3 .

Fig. 1 Fe-Mo Phase Diagram



Note: The numerical values shown are the assessed values. The drawn curves are from thermodynamic calculations and their positions do not always correspond to the assessed values. 